\title{
Laser applications in secondary education (LASE) project at Santa Teresa High School
}

James Sagray

James D. Sagray, "Laser applications in secondary education (LASE) project at Santa Teresa High School," Proc. SPIE 2525, 1995 International Conference on Education in Optics, (13 October 1995); doi: 10.1117/12.224063

Event: SPIE's 1995 International Symposium on Optical Science, Engineering, and Instrumentation, 1995, San Diego, CA, United States 
Laser applications in secondary education (LASE) project at Santa Teresa High School

James D. Sagray

Santa Teresa High School, Science Department

San Jose, California 95123

\begin{abstract}
This manuscript will explain how to bring the LASE Project (Laser Applications in Secondary Education) to the high school physics classroom. The progress made after three years of implementation of the program at Santa Teresa High School will also be discussed. The goal of the project is to bring significant laser technology and optics to the secondary level with a special emphasis on student research and publication. The project has focused on requiring all students in Physics and Honors Physics classes (32/period) to experience laser labs in small groups working throughout the classroom. In addition to receiving this exposure, all physics students were encouraged to do original research projects and to compete for prizes against other California high school students at the Optical Science Fair held at San Jose State University. Students were further encouraged to publish their results in the LASE Log journal.
\end{abstract}

Keywords: laser, LASE Project, student research projects, optics, physics labs, high school optics, high school laser labs, laser applications, optoelectronics

\title{
1. INTRODUCTION
}

Santa Teresa High School is part of the East Side Union High School District (ESUHSD). The district is comprised of ten high schools with a district-wide enrollment of 22,000 students. There are approximately 55 different languages spoken by its students, making it one of the most ethnically diverse districts in the nation. Santa Teresa has an approximate population of 2,200 students. Santa Teresa's student population has changed dramatically in recent years. The school opened in 1974 with a 95\% Caucasian population. The freshman class of 1991/1992 reflected a far greater ethnic diversity with a population of $49 \%$ Caucasian students. Changes in the demands of the business community, the structure of families, and the needs of society has caused the Santa Teresa staff to rethink the process of educating students. The Santa Teresa staff understands the importance of restructuring the school so as to meet the current and the future needs of its students. An important part of the restructuring process is to make technology a vital part of a student's education. Like many high schools, Santa Teresa has suffered from a severe lack of resources. With virtually no compensatory education or discretionary funds, the school, including the science department, was a "technological desert." As science teacher, I was embarrassed by our lack of technology.

As a result of this, I had been exploring new ways to expand technology in my science classes. One promising endeavor was a two week workshop on Laser Applications in Science Education (LASE) Project that I attended in the summer of 1991. This workshop was designed primarily to instruct physics teachers in the use of laser technology in the high school classroom. The LASE Project was a joint project by the National Science Foundation and San Jose State University (SJSU) which was directed by Dr. Gareth Williams. Additional grant moneys were provided by the Optical Society of Northern California, the Laser Institute of America, Tektronix, Inc., Uniphase Corp., Hewlett Packard Co., Laser and Electro-Optics Manufacturers' Assoc., Coherent Inc., Spectra-Physics, Edmund Scientific, Liconix, and IBM.

With the increased use of microelectronics and lasers in industry, optics has been rejuvenated. Optoelectronics has come to the forefront in the development of the next generation of computers and a number of new scientific and industrial devices and processes. This new optics industry based on optoelectronics, fiber optics, laser technology, and optical computing will rise to great prominence before the 21 st century.

Because of the "lag-time" between industrial applications and the publication of high school physics textbooks, most physics teachers have little experience with laser technology. The result is that high school physics courses offer minimal exposure to lasers and associated technology for a more "traditional" approach. The LASE project seeks to change this.

The purpose of the project is to introduce the principles of optics by studying ways to modulate and manipulate laser beams, while taking advantage of the "glamorous" aspects of the laser as perceived by our students. It is 
designed around the use of low power HeNe lasers as the key laboratory tool; however, other equipment is needed. The equipment used is a mixture of relatively expensive equipment, such oscilloscopes and optic benches, and an assortment of inexpensive items, such as small electric motors, mirrors, wiring and photodetector parts. LASE incorporates the use of fiber optics, bar codes, holographic and basic optic technology. The LASE Project has been developed as a laboratory course in the form of a collection of laser-oriented investigations designed to lead the student into research projects. Many of the LASE investigations are oriented around simplified versions of photonic devices constructed and operated to reveal deeper optical principles. LASE culminates with original student laboratory research and with publication in the LASE LOG journal. Students are then encouraged to compete against other high school students for prizes in the Northern California Optical Sciences Fair hosted by San Jose State University's Physics Department.

As I went through the LASE workshop, I saw the LASE Project as a means to expand technology in my physics classroom. Both the state science framework and our own restructuring plan require us to empower the students as "knowledge extenders" who work together in collaborative and problem-solving formats. This project would provide students access to technology, encourage critical thinking, enhance design skills, and offer the opportunity to publish their work. Another key goal was to bring active learners real technology in problem-solving laboratory formats and to evaluate success on the basis of student performance. With these goals in mind, I felt the time was right to bring significant laser technology to Santa Teresa High School.

\section{PROBLEMS EXPERIENCED BY PRIOR LASE TRAINEES}

The LASE workshop was a wonderful experience. I learned a great deal about laser technology and was given many practical ideas that could be used in the classroom. One of the highlights of the workshop was when the original group of teachers trained in the summer prior to ours came and talked about their experiences with the LASE Project in their own classrooms. While enlightening, a very disturbing pattern began to emerge. Almost all the teachers were doing LASE investigations after school with a minimum number of interested students. This often took the form of clubs, extra credit assignments, or science fair projects. The main reason for this was the severe lack of equipment. Many teachers had only one laser and one oscilloscope. Teachers who were doing LASE experiments in class either had a science aide to help the students with experiments while the physics teachers instructed the rest of the class on something entirely different, or they had a small group of students working on LASE investigations while the other members of the class did something entirely different such as working on a worksheet. In both cases, it would take a number of days to rotate a class of 32-35 students through one investigation. Obviously, this is not the most efficient way to run a class.

During the workshop, a LASE handbook on lasers was presented for our assistance. Written laboratory investigations were also provided. Both the handbook and the investigations were written in a form for teacher use and not intended for use by students as a high school lab manual. Since there was a very limited amount of written materials for students, the teacher would need to give a great deal of oral instructions to a small number of students in the lab group. This process again limited the number of students who could be exposed to the laser and optics labs. Most instructors teach five to six periods a day and are given one preparation period. Because most science teachers teach more than one subject in science, the teacher's "prep" period is used to grade papers, prepare labs, and get ready for the next day. There is never enough time for a teacher. It is not uncommon for science teachers to put in a sixty hour work week just to survive the everyday demands now placed on them by the administration and the community. There is little or no time to create or develop new materials for use in the classroom. The result is that the materials never get produced, and the program then withers and dies. I have already seen some teachers stop participating in the LASE Project for the reasons stated above.

\section{OVERCOMING THE PROBLEMS OF IMPLEMENTATION}

Despite the problems listed in section 2, I wanted to have all 32 students doing the LASE investigations at the same time each period. From my view this would take tremendous resources - a minimum of 11 lasers, oscilloscopes, and optical benches. Inexpensive equipment such as little electric motors and photodetectors are additional. The initial start-up cost would be expensive, but once the equipment was purchased, program maintenance would be relatively inexpensive.

I had only one laser and a 17 year old oscilloscope. Other teachers who were involved in the LASE Project were in a similar situation. An optical bench was presented to each participate in my summer LASE workshop, which somewhat increased my meager supply of equipment at Santa Teresa. 
Since the passage of Proposition 13, the lack of money for schools in California has continued to be severe. California's economy has continued to deteriorate due to the added effects of the recession. Fewer tax dollars and competition among different state programs has painted a bleak future for California education. The issuing of state IOU's in the recent past to state workers and vendors has brought this to national attention. State disasters such as earthquakes, firestorms and floods continued to drain the state coffers. In this climate, it would seem impossible that a new program could get off the ground, but that was exactly what I was trying to do. Because I was teaching physics in the "traditional" order with kinematics and dynamics in the first semester and waves, light, electromagnetism, and relativity in the second semester, I had about five months to acquire the necessary equipment to begin the LASE investigations.

It seemed that several things had to be overcome at once to achieve my goal. I had to solicit my local school administration's and community's support, while creating an atmosphere of enthusiasm for my students for a program that did not yet exist. I had to convince my students' parents that this was an important program for their children to experience. The foundation for my materials resource program was based on the building of relationships with the above groups. It was obvious to me, that I could not do this by myself. I also had to write several lab investigations that would be appropriate for my students and seek funds from available grants. I had no illusions that the entire program could be implemented in the first year.

\section{$\underline{3.1 \text { Successes of my resource materials program }}$}

In the first year of implementing the program I receive a total of $\$ 2,900$ from grants. The largest grant came from International Business Machines (IBM) with a value of $\$ 1,000$. My students also did a fund raiser which amounted to a total of $\$ 1,800$. This money was used to purchase the necessary equipment needed to start the project. I also received used equipment from some the local industries which are associated with research in optics and laser technology. During this same period of time I wrote six laser investigations that were appropriate for my high school students, while developing some low cost peripheral equipment.

In the second year of the program, while capitalizing on successes of the prior year, I acquired even more grant money and donated equipment from companies where my students' parents worked. At the end of the second year of the LASE Project at Santa Teresa High School, I had acquired 15 new 1W HeNe lasers, 15 new optical benches with accessories, 15 used $100 \mathrm{MHz}$ oscilloscopes, and 15 new and used autoranging multimeters. I also received various sizes of front surface mirrors and mirror mounts, coated and uncoated lens, prisms, diffraction gratings, and filters. In additional to the above equipment, other accessories were developed and built, such as, photodetectors that fit on the end of a $9 \mathrm{~V}$ battery. Reference books were purchased on topics such as: optics, lasers and holography. Five additional laser investigations were written. This produced a total of eleven laser investigations that my students would experience.

\subsection{Lessons learned}

The above section lacks detail on specific grants sought and fund raising techniques. This is because fund raising is often unique to an area or state. However, I learned some general principles that could be applied to almost any situation or area. Below is a list of lessons I learned "the hard-way". I hope applying the lessons I learned will save you some time.

- Involve your local administration in your project

- make them believers

- show how this program can help in restructuring your school

- enlist them to help you seek funding sources and provide help in grant writing

- encourage your local administrator get your district administrators excited

- do not take "no" for an answer

- Involve your students' parents

- make believers out of them

- remind them that they are helping their children to be more competitive in the 'real' world

- show them that students who publish their work will have a competitive edge when they apply to college

- empower your parents to provide equipment or funding for you

- Pursue industries for monetary or equipment support

- aggressively pursue all ideas, personnel, and companies for support

- use all means of communication at your disposal 
- demonstrate how support is good publicity for their company

- start with, but do not limit yourself to, local industries

- remember that most of your efforts will not "pan-out", but eventually you will be successful

- Empower your students to help in fund raising

- demonstrate to them a "neat" lab they will be able to do

- explain the advantages of the program to them

- provide incentives for them to help raise funds

- avoid required fund raising to earn a certain grade - this only fosters resentment towards the program

- expect a maximum of $50 \%$ of your students to actively help in fund raising, no matter what incentives are offered

- Invest time to write an exceptional proposal

- be willing to modify your original proposal to fit the requirements for each different grant

- do not waste time applying for grants that require an immense amount of work for little monetary return

- Stay positive and do not look for reasons why fund raising will not work

- actively seek ideas from staff, parents, and students

- delegate, when possible

- Capitalize on your successes, stay aggressive, with your sights still set on your goal

\section{THE ELEVEN LASE INVESTIGATIONS AT SANTA TERESA HIGH SCHOOL}

At the beginning of the school year, the students were trained and tested on laser safety. The students then performed two laser innvestigations. After completing a unit on waves, ten laser labs were completed by all my students over the next two months. The students worked in groups of two or three. These laser investigations were dispersed among a number of other labs related to optics and light. Below is a brief description of each of the eleven laser investigations now being utilized in my physics curriculum. Comments and observations about student involvement has also been included.

\subsection{Using trigonometry of right triangles}

This investigation which is introduced at the beginning of the school year, brings a lot of excitement to the course. This investigation has four primary goals for the students to achieve. The first goal is to understand that the laser is a laboratory tool and not an entity unto itself. The second goal is, to allow the student to operate the laser with "handson" exerience. The third goal is to allow the student to utilize trigonometry of right triangles in an interesting way, while demonstrating the relevance of the trigonometry. The final goal is to introduce the concept of percentage of error. The student's task is to calculate the height and width of the room by measuring the angle through which the laser is pivoted and the distance its pivot point is from the room's wall. After this, they are to actually measure the wall's height and width and calculate their percentage of error.

Using a protractor and a pair of wood blocks to set the laser on, most students had a percent of error of less than five percent. The students' enthusiasm was quite high. Many students were learning that trigonometry was a tool just like a laser and actually had a practical use, rather than being just something to know.

\subsection{Applying the laws of sines and cosines}

This investigation occurs soon after the above lab. The scenario of this investigation is that the students are surveyors which must measure the distance between two trees that are on the other side of an impassable canyon. All measurements must be done from the surveyor's side of the canyon. The main purpose of this lab is to reinforce the understanding and use of the law of sines and cosines.

The Applying of the Laws of Sines and Cosines investigation turns out to be incredibly complex for beginning physics students. The student must establish a base line from which he/she makes his/her measurements while measuring an angle to each of the trees from two different positions at each end of the base line. Because the students are making one distance measurement and four angle measurements, errors compound upon one another as they do their calculations. It is not unusal for lab groups to have between a five and twenty percent of error for the distance between the trees. The experience is good for the students, while testing their understanding of the law of sines and cosines. 


\section{$\underline{4.3 \text { Reflection }}$}

The reflection lab is the first LASE investigation that takes place after our study of waves, and it serves as an introduction to my light unit. In part one of the investigation, students use a front surface plane mirror, a laser and a paper protractor to confirm the law of reflection. In part two, the students are to design an experiment which shows that the angle of incidence equals the angle of reflection without the use of a protractor.

Besides introducing the concept of the law of reflection, the students had an opportunity to use an optical bench for the first time.

\subsection{Refraction}

The refraction lab investigation introduces the concept of Snell's Law by allowing the students to discover that the ratio between the sine of the angle of incidence and the sine of the angle of refraction equals a constant. The students had to find the index of refraction for both water and glycerol. The equipment used is a semicircular dish, a laser, and polar graph paper.

The advantage of using a laser was that the students could actually see the beam bending in the liquid. The semicircular dish was used so that the laser beam would not refract as it left the curved side of the dish. This occurs because the laser beam cuts through the radius of the dish and always emerges perpendicular to the curved surface making it easier for the students to measure the angle of refraction. To make the beam easier to see in the water, a slight amount of $\mathrm{MgCO}_{3}$ was added for a reflective surface. In the glycerol, the reflective surface were tiny air bubbles which were added by shaking the glycerol bottle prior to pouring it into the dish. Generally speaking, the students get exceptional results.

\subsection{Critical angle and total internal reflection}

Using the same equipment as in the prior lab, students explore the concept of critical angle and total internal reflection. In this lab, however, they shine the laser through the curved side of the semicircular dish, always making sure that the emerging beam leaves through the center of the flat side of the dish. They find the critical angle of water in this manner.

I had the students explore internal reflection by having the students slide the dish perpendicular to the laser beam as it was shot through the flat side of the semicircular dish. Many students discovered that they could shine the laser beam on the edge of the dish, causing the beam to follow the inside curvature of the dish's plastic wall. This generates a great deal of excitement in class.

\subsection{Index of refraction by minimum deviation}

In the two investigations above, the students were using the same shaped dish. I wanted them to try another shape like a hollow prism. This meant introducing the concept of minimum deviation. I found that commerical hollow prisms were very expensive. So I built hollow prisms out of glass microscope slides and scrap glass or petri dish lids. I tried to find liquids with index of refraction values that were not available in the student physics text. Some of these liquids included: peppermint oil, bitter almond oil, olive oil, cedarwood oil, pinewood oil, clove oil and mineral oil.

The students usually had less than three percent of error. I found these results remarkable, considering my crudely built hollow prisms. Since many of the liquids are very expensive I usually pour the liquids myself at the beginning of the day and return them to their respective bottles at the end of the day to be used during the following year. I have the last period of physics students wash the hollow prisms.

\subsection{Diffraction gratings}

Young's experiment has already been introduced to my students using a double slit, an incandescent light source, and colored filters. The purpose of this investigation is for the students to measure the spacing between the lines of a commerically produced holographic diffraction grating, using a laser. Students were also asked to bring a compact disk to class. Compact disks act as a wonderful reflective diffraction grating. 
Some students each class period would always ask if the laser would damage their disks. This would lead to a wonderful discussion on how a CD player works. Students would really have to apply what they had learned from Young's experiments to find the line spacing of a diffraction grating. Often students would be huddled in groups discussing how this could be accomplished. A great deal of satisfication was gained by the students when they were able to complete the lab with acceptable results.

\subsection{The laser beam and the Inverse Square Law}

This is the first LASE investigation that explores some of the characteristics of the laser. The question posed in this lab is whether the laser follows the inverse square law as does other ordinary light sources. Several concepts are introduced in this lab, such as, developing range-finding "calibration curves", folding the laser beam with mirrors, measuring the diameter of a laser beam, and calculating irradiance. Students are then asked to observe the difference in the lab when doing the investigation with the room lights on and with the room lights off..

This lab usually takes two 55 minute lab periods. The students really enjoyed this lab. Because of the configuration of my room, I would have the students move all the furniture to one side of the room. This would allow my students to work on the floor. This made it very convenient for each group to lay out a $15 \mathrm{~m}$ fiberglass measuring tape across the room with the laser at one end. The device for measuring the laser beam's diameter was simply a $3 \times 5$ card with ten interval centimeter graph paper glued to its surface. This card was then mounted on a ring stand with a clamp and set on the floor next to the tape. This proved to be a very stable situation for making measurements. The student's results provided active discussions between class members concerning whether the laser obeyed the inverse square law. Since all of my lasers are made by the same manufacturer, some students wanted to test a variety of different lasers from other manufacturers. Limited resources made this impossible.

\subsection{Scanning the Gaussian Profile of a laser beam}

In the last investigation, students recognized that it was difficult to establish where the edges of the beam actually ended. Unbeknownst to the students, scientists recognized that the brightest portion of the beam is located at its center which continually decreases to the edges. The fuzzy nature of the beam's profile theoretically never drops to zero. The students are then asked if the laser beam was uniform in brighteness across its center. Again, several new concepts are introduced in this investigation. Examples of these concepts include: the Gaussian Profile, scanning techniques, how a photodetector works, and the use of a multimeter. The theory behind the investigation is that the voltage produced by the photodetector (which can be used to indicate the amount of light) can be measured by a multimeter. By graphing the voltage versus the distance across the beam's diameter, a Gaussian Profile of the laser beam can be produced.

Before this lab could be done, I had to design and build a photodetector system that was inexpensive and compact for every lab group. Plans and diagrams are provided later in this paper for my photodetector system that mounts on the end of a $9 \mathrm{~V}$ battery. While this investigation should take only one period, experience has taught me that the students need time to learn how to connect and manipulate a variety of equipment which includes an optical bench, a laser, a photodetector, as well as, various mounts and clamps. Critical alignment is difficult because the students are folding the laser beam across the room to a mirror while positioning the reflected expanded beam where the photodetector can scan across the beam's diameter. Some of the students found this experience very frustrating because they literally had to manually push the photodetector across the beam's diameter at discrete intervals (I have no $\mathrm{x}$, y, stages). After the first day, students become familiar with the equipment. On the second day, the students must start the investigation from the beginning, but, they move much more rapidly to complete the lab.

\section{$\underline{4.10}$ Bar code Reading}

The bar coding is the most difficult investigation for the students in the setting up of equipment. In fact, this lab requires almost every accessory that comes with my optical benches. The basic idea behind the investigation is that the students will be scanning a stationary target (bar code) with a moving laser beam using the "wobbler" technique. This technique produces a circular beam by mounting an angled mirror on a small rotating motor. The circular beam pattern cuts across the bar code on a glass slide. Instead of the photodetector reading a reflected beam, it will sense a beam traveling through a "bar coded" glass slide. Analysis of the photodetector output will be done by using an oscilloscope. Having the students measure the width of the bars on their glass slide prior to placing it in their optical system and then measuring the time it takes to cross the bars via an oscilloscope, they can then calculate the speed of the scanning pattern in $\mathrm{mm} / \mathrm{s}$. Without changing the speed of the motor, the students make a new bar code and insert it 
in the place of the original bar code on the optical bench. They are then asked to determine the width of the solid bars of the new bar code.

It is not atypical for students to have 20 percent of error on the actual width of the bars on their second bar code. There are many places where students can make errors from equipment usage to calculations. However, the experience was very worthwhile, and students had to stretch their patience in regards to alignment techniques. They had to learn how to manipulate and use a lot of different equipment. The investigation lead to some very interesting dicussions on how a real bar code reader works in stores. Some students actually acquired technical manuals on bar code readers and were comparing their optical system in this investigation with the operation described in the manuals.

\subsection{Holograpy}

This lab, by far, is the favorite investigation for all of my students. Students cannot wait to get to this investigation. At my high school, many students say they sign up for my physics classes just so they can make holograms. It is a great recruiting "plus" for your next year's physics classes. The technique employed uses the coherent light from a HeNe laser. Students shine an expanded laser beam through a photographic plate which will strike an object and then reflect back through the plate. The incident and reflected beams set up an interference pattern which is recorded on the plate. The recorded interference pattern makes a permanent record of the light wave's intensity and phase. When the hologram is placed in a bright point source of light (such as light from the sun, overhead projector, halogen lamp or clear incandescent bulb), the observer sees their object as green and threedimensional.

I invite students to bring in shiny metal objects that have sentimental value to them. This makes their hologram even more special to them. Students often fail to see the interconnection between physics and other subjects they study. When doing an experiment, there is a certain elegance and creativity in its design and set up. The experimental results can often be delightful to look at. In holography, the artist meets the physicist. Students, with some preplanning, can create beautiful arrangements of objects with unique and wonderful themes. I often have my students doing the bar coding investigation simultaneously with hologram production. I have created an exposure room and darkroom out of PVC pipe and 6 mil black plastic that can be set up and taken apart. Separating the exposure room from the darkroom allows students to have an assembly-like production line which maximizes classroom time. The first year I had my students make holograms, we had approximately an 85 percent success rate. With some "fiddling" and gained experience, the success rate has risen to approximately $90-95$ percent.

\section{RESULTS OF THE LASE PROJECT FOR THE LAST FOUR SCHOOL YEARS AT SANTA TERESA HIGH $\underline{\text { SCHOOL }}$}

Over the past four school years since the LASE Project was implemented, over 600 students have experienced between six and eleven laser labs. It should be emphasized that the LASE investigations were only part of a series of lab investigations in my unit on light and optics.

It is quite clear from the enthusiasm generated by students that the LASE investigations greatly enhanced my light and optics unit. One of the ways this enthusiasm can be illustrated is by the motivation of several students wishing to particicate in the three Northern California Optical Science Fairs, which were held at San Jose State in the spring of 1992 through 1994 and sponsored by the SPIE.

Most of the students had a difficult time coming up with an idea for their research projects. Many of my students thought that they would come into the classroom, do their experiments, and be done in a couple of hours. They saw a new side to science. Many problems occurred that they did not anticipate. Their labs required "fiddling", revising, and then rewriting. They were getting a dose of real science. Many became discouraged and wanted to quit.

Every science room at our school is shared by more than one science course during the day. There is no space for storing long term projects. This meant constantly setting up and tearing down equipment for projects. I found myself running around helping many students with their projects, while gathering and putting away equipment. It was an exhausting experience.

I have a great deal of respect for these students who were willing to give up their free time to attend Monday and Wednesday nights from 6:00-9:30 PM and many Saturday mornings from 9:00 AM-1:00 PM to do their research. It surprised me that no one dropped out. 
High schools from as far north as Sacramento and as far south as Salinas participated. The competition was divided into two separate categories: table-top exhibits and poster displays. Judges comprised of university professors, teachers, and professionals in the optics and laser industries graded each student's research on scientific merit, orginality and clarity of explanation. All students were asked penetrating questions regarding their projects, as well as, being quizzed with hypothetical "what if" questions related to their research.

In the first annual Optical Science Fair, judges, industrial representatives, professors, and other high school teachers were amazed at the number of students (14 in all) competing from Santa Teresa High School. Most high schools averaged two students in attendance. After viewing the displays, one high school teacher jokingly said to me that he thought he had attended the Santa Teresa School optics fair. Many inquires were made about how I accomplished this feat. Awards ranged from first to third place for each of two project categories. My students took second place and third place in the exhibits category and a third place in the poster category.

In the spring of 1993, the second annual Optical Science Fair was held. This fair was placed on a date that corresponded to our spring break. Because of this, it was difficult to convince students to participate. They knew it would be a lot of hard work, while having to give up part of their vacation. This resulted in only eight students competing from our school. In the fair there were only two awards given for each category. Two of my students took first place in each of the categories.

I had much better results in the third annual Optical Science Fair of 1994. There was no conflict with the students' spring break. Seventeen Santa Teresa students participated in the fair. This year there were four awards for each category. Of the eight possible awards, my students took seven of them. They won two first places, one second place, two third places and two honorable mentions.

Below is list of of some of my students' research project titles that were entered in the three Optical Science Fairs:

- Reflective Bar Code Scanning

- Polarization of Laser Light by Scattering of Particles

- Measuring the Effect of Voltage on Motor Speed Using a Laser

- Determining Your Eye Vision Using the Speckling Effect of a Laser

-Holographic Interferometry

- Measuring the Wavelength of a Laser by Bouncing the Beam off a Steel Ruler
- Poor Mans Sound Oscilloscope

- Index of Refraction of a Cooling Substance

- Analyzing Spirograms Produced by a Laser

- Measuring Fingerprint Grooves with a Laser

- Measuring the Turbidity of a Liquid Using a Laser

- Measuring the Diameter of a Hair Using a Laser

- Measuring the Gap Between Wet and Dry Pantyhose Fibers by Using a Laser

Unfortunately, there was no Optical Science Fair held in 1995. This was due to the fact that those who spent countless hours of volunteer work on the fair were given a two year sabbatical from their duties at San Jose State University. It is my hope that the Optical Science Fair will be held again in 1997.

Several of my students then published their research work in the LASE LOG journal. Due to budget constraits, the LASE LOG had to terminate publication for the last two years. However, just recently, the LASE LOG has been funded for publication again. It was too late for my students to publish their results this year, but I am looking forward to the publication of their research in future years to come.

\section{SIMPLE TO BUILD EQUIPMENT}

Lack of money for schools has necessitated the invention and construction of relatively inexpensive equipment as compared to their commercial counterparts. All of the equipment can be made by high school students in class or the school metal, wood, and/or electronic shops.

\subsection{Hollow prism construction for minimum deviation lab (unit cost - less than $\$ 2.00$ )}

\section{$\underline{6.1 .1 \text { Materials }}$}

3 clear microscope glass slides

1 small thin rubber band

2 tubes of GE Silicon II (clear) glue \& seal
1 glass plate or petri dish lid

1 roll of transparent tape
1 sheet of paper

1 pair of scissors 


\subsubsection{Procedure for construction}

1. Begin by measuring the length of a glass slide. Using this length, draw an equilateral triangle on a sheet of paper and cut it out. You will be using this triangle pattern to mark the placement of the glue on the glass plate or petri dish lid.

2. Tape the paper triangle to the bottom center of the glass plate on the opposite side of which you will place the glue (see figure 1 below).

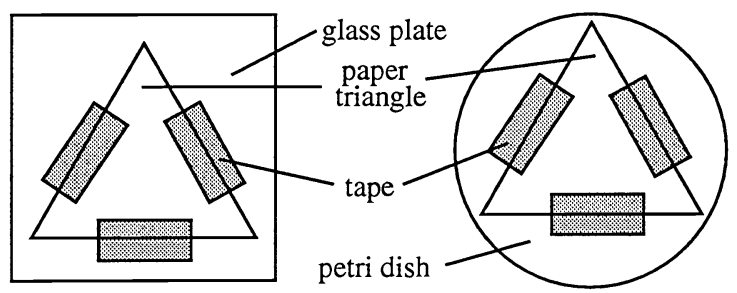

Figure 1: Hollow prism

3. Apply a smooth line of glue to the glass plate, being careful to follow the outside edges of the paper triangle.

4. Place the glass slides in the glue and move them back and forth to assure a good seal. Be sure that the end of the glass slides meet and are perpendicular to the glass plate.

5. Lightly bind the top of the hollow prism assembly with a thin rubber band. Apply a thin, smooth bead of glue around the entire outside base of the prism and let set approximately two hours.

6. Remove the rubber band and seal the outside vertical edges of the glass slides. Let set about an hour.

7. Cut the tip of the second tube of glue into a "V" shape. This will allow the tip to fit into the inside angles of the prism. Now seal the inside vertical edges of the prism. Let the glue cure for approximately 24 hours.

\section{$\underline{6.2 \text { Optical bench design and construction }}$}

\subsubsection{LASE optical bench (unit cost - \$275)}

This optical bench was designed after the first LASE summer workshop in 1990 by Robert Zafran and Patrick Joyce. I highly recommend this optical bench system if you can afford it. The main bench which is $75 \mathrm{~cm}$ in length is made of anodixed aluminum with five interlocking right angle rod blocks. It comes with ten $1 / 2 \times 8$ inch steel rods with $1 / 4 \times 20$ threaded ends for attaching lasers and other optical equipment. They also designed quick insert mounting brackets that allow the steel rods to be attached to each other in a " $t$ " configuration. If you are interested in this optical bench, call Robert Zafram, Product Development Manager of Creative Science Products, at (408) 2666249 for more information.

\subsubsection{C-clamp optical bench (unit cost - $\$ 15$ to $\$ 40$ )}

This system was designed by Steve Honett at Dublin High School. This optical bench does not have the elegance of the LASE optical bench discussed above, but it is an excellent inexpensive alternative. It allows the student to firmly attach his/her equipment easily and quickly. The price variation is dependent on the local price of materials and whether your high school has a metal shop in which the bench can be made. See figure 2 on the next page. 


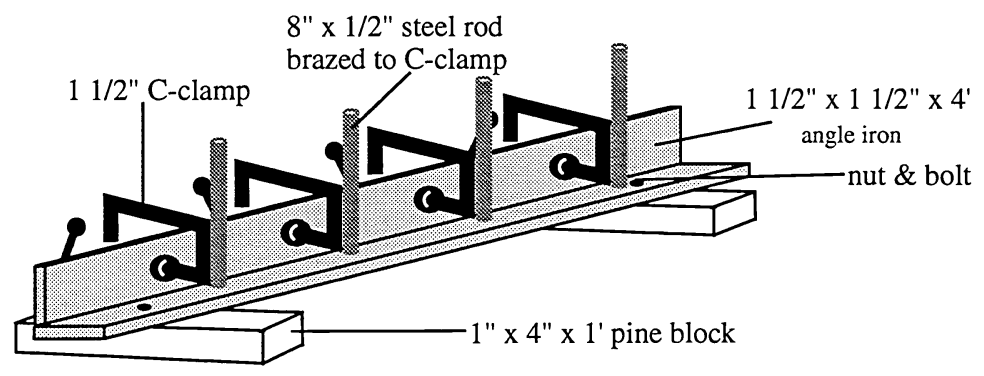

Figure 2.

\subsubsection{Pine wood optical bench (unit cost - under $\$ 10$ )}

I invented this optical bench as a cheap alternative to the two benches previously discussed. All the materials are easily found at local lumber and hardware stores. This bench requires no special equipment for brazing metal. However, a table or radial arm saw and drill are needed. This bench allows your optical equipment to be solidly tied together, but adjustments on the bench are somewhat awkward. To make this bench, rip a 1" $\mathrm{x}$ 4" $\mathrm{x} 4$ ' piece of pine wood into three long strips, being sure that the middle strip is a minimum of $21 / 2$ inches wide. Place the three strips together and drill a hole through their sides at each end (see Figure 3). Using $1 / 4$ inch washers, create a channel between the wood strips and place a 4 inch machine screw through the wood and washers and tighten together with a hex nut. Cut platforms to size, being sure to cut a slot in the optical platform to hold the mirrors and/or the lenses. Assemble the rest of the bench as indicated, using machine screws, washers, and wing nuts.

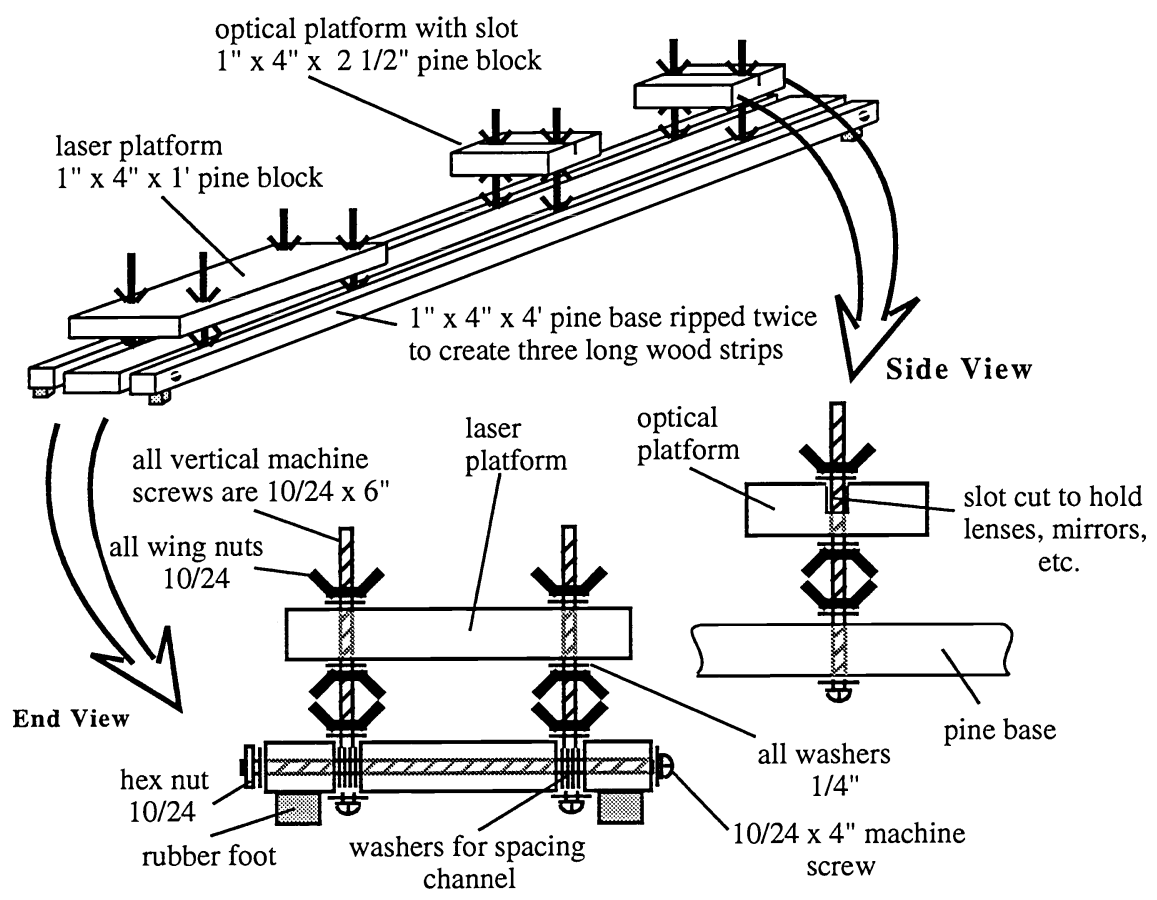

Figure 3.

\subsection{Photodetector (unit cost $-\$ 4$ to $\$ 8$ )}

This easy-to-make photodetector system is built on a $9 \mathrm{~V}$ battery clip (see Figure $4 \mathrm{~A} \& 4 \mathrm{~B}$ ). The whole system just snaps onto the top of the battery, which is held in place on the optical bench by a coupler nut and battery holder assembly(see Figure 5). Modifications to the assembly could be necessary, depending upon the type of bench used. 
The amount of resistance needed by the bias resistor depends upon the photodetector used. The range has been found from $3 \mathrm{k} \Omega$ to $4 \mathrm{k} \Omega$. I have been using an infrared detector (cat. no. 276-142) sold at Radio Shack with a $3.3 \mathrm{k} \Omega$ resistor. But be careful, because their stock is constantly changing with different detectors having the same part number. I used the detector that is gold in color with three leads coming out of the back. Another source for detectors is Circuit Specialists, P.O. Box 3047, Scottsdale, AZ 85271. Their infrared phototransistor (cat \# ME 351-1152) works well with a $3 \mathrm{k} \Omega$ bias resistor. Digi-Key Corporation, 701 Brooks Avenue South, Thief River Falls, MN 56701 stocks a phototransistor (cat \#PN168PA-ND) which performed well with a $4 \mathrm{k} \Omega$ bias resistor. The price varies with the amount of parts purchased. Once I have finished construction and testing the photodetector system, I cover all exposed circuitry with G.E. Silicone II adhesive for insulation and strength. Figure 6, shows the circuitry diagram of the photodetector system.

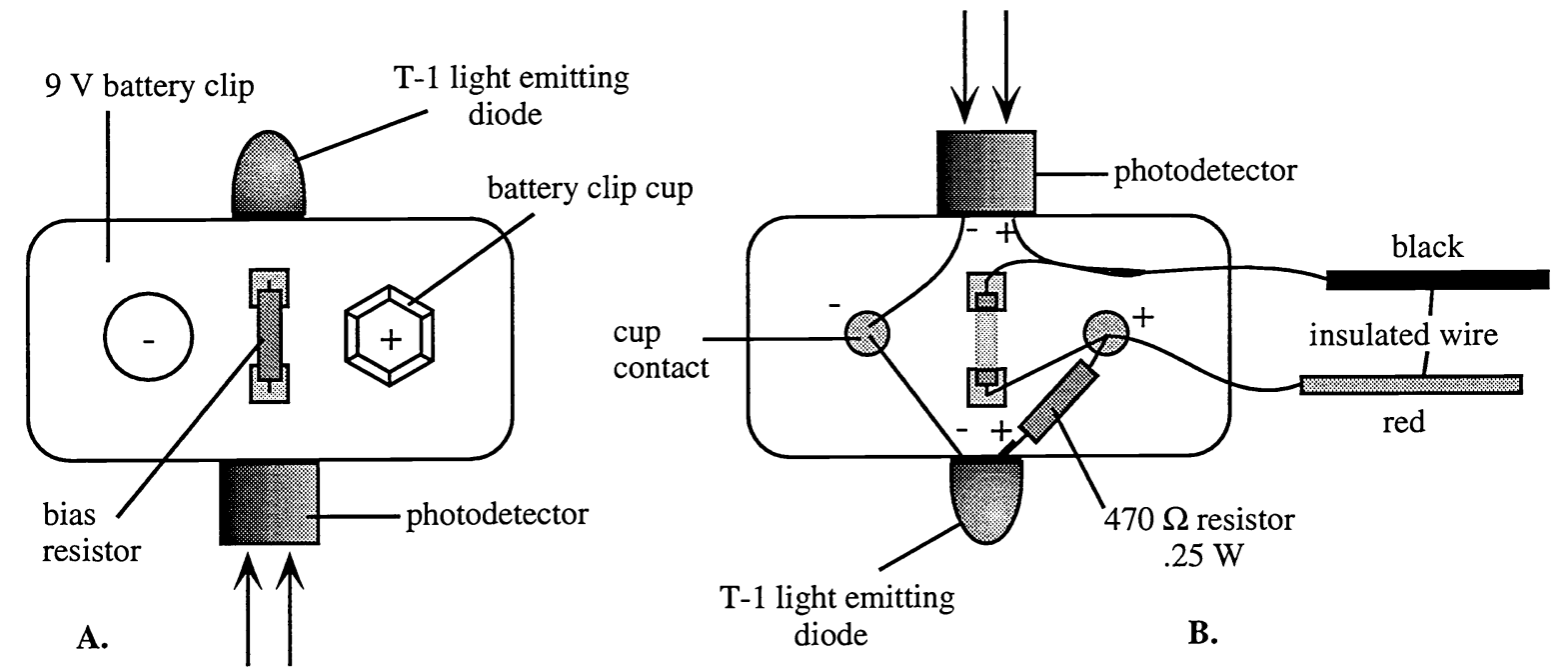

Figure 4: Photodetector system on 9 V battery clip

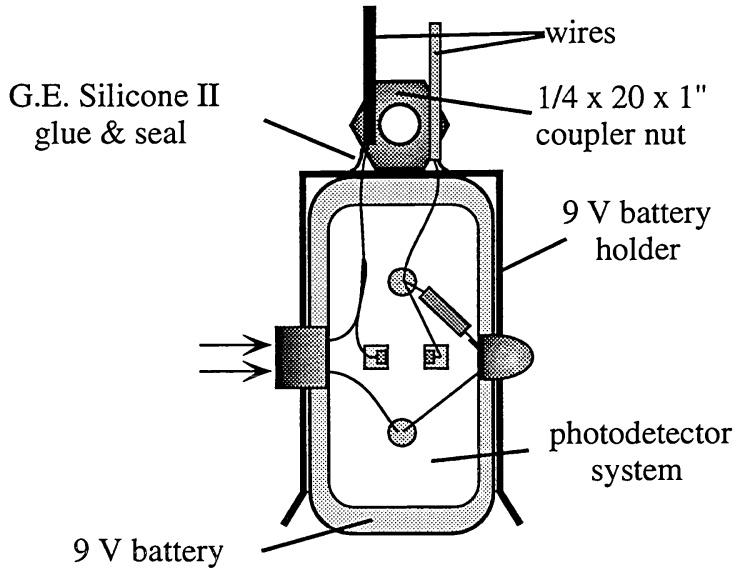

Figure 5: Photodetector system on $9 \mathrm{~V}$ battery

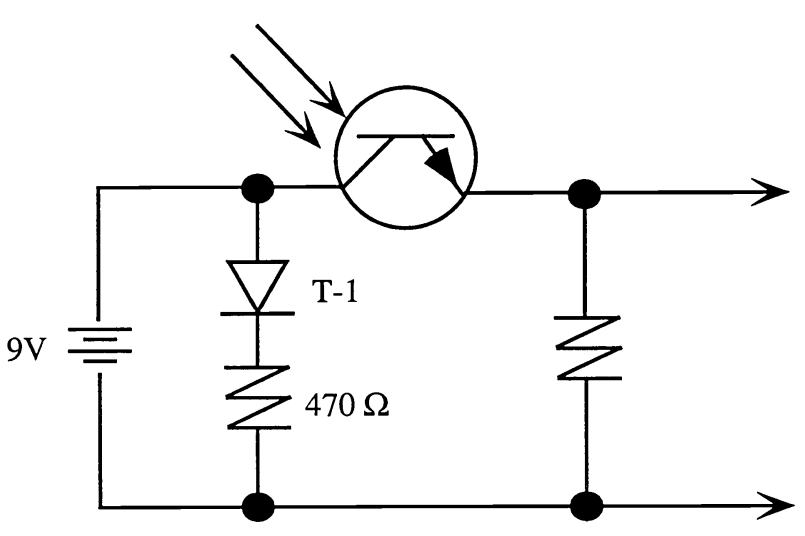

Figure 6: Photodetector system circuit diagram

\section{ACKNOWLEDGEMENTS}

The author wishes to thank Dr. Gareth Williams for all of his ideas and encouragement as the LASE Project progressed at Santa Teresa High School. I would also like to thank the Optical Science Fair volunteers who put in countless hours to make it a success for the participants. 